\title{
A DESIGUALDADE DE GÊNERO NO EMPREENDEDORISMO EM RONDÔNIA, DISCUSSÃO NO CONTEXTO NACIONAL E REGIONAL
}

\author{
GENDER INEQUALITY IN ENTREPRENEURSHIP IN RONDÔNIA, DISCUSSION \\ IN THE NATIONAL AND REGIONAL CONTEXT
}

\author{
Pedro Paulo Almeida Martins ${ }^{1}$
}

RESUMO: O presente artigo visa compreender e responder às dúvidas acerca do papel da mulher no mercado, ou seja, ramos de negócios que se enquadram, estudo do empreendedorismo feminino em Rondônia com intuito de analisar o percurso das empreendedoras e desenvolvimento feminino das empresas de pequeno, médio e grande, sendo trabalho informal rondoniense. Segundo dados do PNADc e DIEESE, no cenário nacional, aumentou a taxa de informalidade para 41,1\%, em 2020, a informalidade, trabalhadoras informais ocupadas, já em nove estados a informalidade bateu recorde em 50\%, em II estados, através destes pressupostos, faremos levantamentos de maneira qualitativa, levantar dados.

Palavras- chave: Agressão à mulher. Desigualdade de gênero. Empreendedorismo feminino.

ABSTRACT: This article aims to understand and answer doubts about the role of women in the market, that is, business lines that fit, the study of female entrepreneurship in Rondônia in order to analyze the path of female entrepreneurs and female development of small businesses, medium and large, being informal work in Rondônia. According to data from PNADc and DIEESE, in the national scenario, the informality rate increased to $4 \mathrm{1.} \%$, in 2020, informality, employed informal workers, while in nine states informality reached a record of $50 \%$, in II states, through these assumptions, we will do surveys in a qualitative way, raise data.

Keywords: Assault on women. Gender inequality. female entrepreneurship.

\footnotetext{
I Bibliotecário Documentalista do Instituto Federal de Rondônia- IFRO. Acadêmico do curso Direito na Faculdade Católica de Rondônia- FCR e graduando em Ciências Sociais na Universidade Federal de Rondônia - UNIR, Porto Velho, Brasil; Pedro Paulo Almeida Martins, Bibliotecário, tecnólogo em Gestão pública, 4 titulações de pós-graduado: Especialista em Gestão Pública, metodologia do ensino superior em Língua Portuguesa, Biblioteconomia e MBA em Governança e Gestão Administrativa, , Email: pedropaulogestorpublico@gmail,com, currículo Lattes: http://lattes.cnpq.br/395i670487194507 Orcid: https://orcid.org/oooo-ooo2-3490-8784
} 


\section{INTRODUÇÃO}

Mulheres empreendedoras em Porto Velho, como é o mercado na sociedade porto-velhense frente ao machismo na sociedade local, a disputa de espaço de mercado ocupado pelas empreendedoras.

$\mathrm{Na}$ cidade porto-velhense encontra-se uma grande gama de profissionais informais mulheres que sobrevivem de diversos ramos nas vendas digitais em Porto Velho. Compreender as dúvidas acerca do estado do empreendedorismo feminino em Porto Velho, a trajetória das empreendedoras e desenvolvimento de empresas, será o desafio para achar respostas através dos dados do observatório do Sebrae.

Analisar o perfil das empreendedoras femininas, qual potencial das mulheres que estão em ascensão, frente ao mercado de Rondônia, seja empresa média, pequena e grande empresa.

Martins (202I) quando falamos em desigualdade, não se pode desconsiderar algo destoar o desrespeito na disparidade de gênero, seja ato de preconceito e desigualdade que paira na sociedade.

A violência começa de forma sútil, nos lares, infelizmente, para algumas pessoas, sem demonstrar estranhamento, seja diante da desigualdade no mercado de trabalho, vale debruçar para explicar a violência contra mulher no Brasil, a seguir:

Assim define os autores (MARTINS; NASCIMENTO, 202I, P.3) A $^{23}$ A
violência de gênero está sim, presente na cultura de todos os países,
ainda que independentemente do seu grau de desenvolvimento, é
possível verificar bem como registrar seja em maior ou menor escala.
Quando o assunto é falar de questões culturalmente, esta temática
provoca conflitos e até mesmo divisão de opiniões por um questão
historicamente e vem desta forma podendo afirmar que a mulher
vem sendo socialmente oprimida de acordo com valores específicos
de uma determinada época, ou seja, provoca uma confirmação

\footnotetext{
${ }^{2}$ MARTINS, Pedro Paulo Almeida; NASCIMENTO, Marla Anaiê Belfort. O PROBLEMA SOCIAL COM A VIOLÊNCIA DE GÊNERO COM A MULHER: UM DESAFIO NA SOCIEDADE COM O ENFRENTAMENTO DESENFREADO POR QUESTÕES E CUIDADOS COM O DIREITO À VIDA. Revista Ibero-Americana de Humanidades, Ciências e Educação- REASE, São Paulo, ano 2021, v. 7, ed. 5, p. 792-791, 4 maio 2021. Disponível em:<

https://periodicorease.pro.br/rease/article/view/1240/563> Acesso em:I9 de Dez de 2021

${ }^{3}$ MARTINS, Pedro Paulo Almeida; NASCIMENTO, Marla Anaiê Belfort. O PROBLEMA SOCIAL COM A VIOLÊNCIA DE GÊNERO COM A MULHER: UM DESAFIO NA SOCIEDADE COM O ENFRENTAMENTO DESENFREADO POR QUESTÕES E CUIDADOS COM O DIREITO À VIDA. Revista Ibero-Americana de Humanidades, Ciências e Educação- REASE, São Paulo, ano 202I, v. 7, ed. 5, p. 792-791, 4 maio 2021.Disponível em:< https://periodicorease.pro.br/rease/article/view/1240/563〉 Acesso em:19 de Dez de 2021.
} 
sobre quem provoca tal violência são diretamente influenciados pelas principais instituições sociais que em muitos momentos da história do mundo apresentam a figura da mulher sendo totalmente prejudicada e em muitos destes episódiostendo suas vidas ceifadas por um erro, cujo estes contribuíram e ainda contribuem para disseminar uma ideia deturpada de que esta é um ser inferior, frágil e com instintos de proteção apenas.

Martins (202I) A violência contra a mulher no Brasil é alarmante no cenário da cidade a situação não é diferente os números registrados pela Sesdec assim como nas últimas notícias mostram casos de violência contra a mulher não incomum.

Apesar da existência de um marco legal sore o feminismo. Além disso, Lei n.o ${ }^{\circ}$ Io de 2015 sore o Suicídio Feminino como Circunstância Elegível para Homicídio e Artigos. I. - da lei n. -9.072 de 25 de julho de 1990 que relaciona o crime de homicídio de mulher como crime hediondo lei n. ${ }^{\circ}$ II.30 2006 os números continuam crescendo evidenciando a necessidade de oras de conscientização de um setor municipal, executivo, na educação básica.

Conforme o levantamento de dados do relatório da Sesdec, consta o número total de vítimas por lesão corporal (violência doméstica) em Rondônia no ano de 2018 foi de 4106, em 2019 foi de 3767, em 2020 teve uma maior incidência de 4 II6 vítimas, números de feminicídio com destaque em 2020, com 7 vítimas, já em 20197 vítimas e 2021 com 6 vítimas.

Violência e seus métodos de reconhecimento e prevenção a lei fornece um caminho seguro para as vítimas de tais atos de ordem pública remediar os problemas sociais no social.

A lei também exige que educadores e/ou suplentes nas redes públicas ministrem e desenvolvam atividades sore o tema para que a sociedade civil na totalidade possa debater e refletir.

(MARTINS; NASCIMENTO, 202I,p.3-4) ${ }^{4}$ Diante da era da sociedade da informação, no mundo globalizado, temos maior acesso à informação pelas tecnologias de comunicação, o que leva informação em tempo real, integral e instantâneo a esta civilização. A sociedade está enfrentando o maior problema social de todos os tempos, a violência

\footnotetext{
${ }^{4}$ MARTINS, Pedro Paulo Almeida; NASCIMENTO, Marla Anaiê Belfort. O PROBLEMA SOCIAL COM A VIOLÊNCIA DE GÊNERO COM A MULHER: UM DESAFIO NA SOCIEDADE COM O ENFRENTAMENTO DESENFREADO POR QUESTÕES E CUIDADOS COM O DIREITO À VIDA. Revista Ibero-Americana de Humanidades, Ciências e Educação- REASE, São Paulo, ano 202ı, v. 7, ed. 5, p. 792-791, 4 maio 2021. Disponível em:< https://periodicorease.pro.br/rease/article/view/1240/563> Acesso em:I9 de Dez de 2021
} 
doméstica, aprender a conviver sem acirramentos dos polos binários, entre mulher e homem no mesmo espaço, em casa, entretanto o índice da violência contra as mulheres subiu, os números vêm aumentando, diante da pandemia global

Nos termos do artigo I. ${ }^{\circ}$ da lei n. ${ }^{\circ} 93996$ dispõe que "a educação compreende o desenvolvimento de processos de formação para a vida familiar convivência humano trabalho instituições de ensino e pesquisa movimentos e organizações sociais, sociedade civil e atividades culturais", assim em consonância com a CRFB de 1988 com as recomendações do artigo 205 e do artigo 206 da Constituição Federal.

Segundo Martins (2021) Agressões às mulheres, desde desigualdade salarial aos suicídios ocorrem cada vez mais no exercício dos direitos civis isso requer um processo educativo para evitar o pedágio de morte, o lema deve ser: "Mulher sem briga" e "Briga de família não dá certo” oferecendo palestras de divulgação com alunos pais e comunidade em geral para evitar potenciais futuros abusadores papel fundamental.

O valor público é reduzir o número de mortos estatisticamente significativo enquanto a agressão doméstica persiste na sociedade em geral nos bairros mais pores de Porto Velho este pode ser a raiz do problema atacando o elemento educacional devido às leis rígidas tem causado esses distúrbios, o problema precisa ser enfrentado para evitar o modelo cultural agressivo de patriarcado e machismo agressivo. Integrado na sociedade funcionará sistematicamente para evitar a origem do patriarcado que é um modelo cultural como afirmam Lévi-Strauss e Durkheim concordando com fatores externos.

As pessoas nascem e as leis são integradas à sociedade para serem seguidas não para criar leis mais rígidas, mas para levar, o processo educacional em conjunto.

Martins (2021) A cidadania tem que ser feita desde a infância tem que incutir nelas formar a educação certa porque uma criança hoje criada em padrões culturais disfuncionais lutando em um lar pode se tornar um potencial invasor no futuro. Sensibilizar nas escolas e comunidades através da mediação escolar para o impacto da agressão nas mulheres infelizmente as crianças sofrem com estes problemas que dificultam a socialização dos alunos.

\section{METODOLOGIA}

Diante da pesquisa, buscaremos por meio da construção da sensibilidade de conhecer o mercado feminino, explicar este fenômeno social, com objeto de pesquisa, as 
pessoas, as empreendedoras de Rondônia, suas atitudes e comportamento no mercado, efetua-se necessária uma reflexão acerca do papel da mulher no páreo competitivo do mercado informal ou formal destas mulheres que se esforçam e empreendem de maneira crescente na Pandemia, logo entender este mercado é um desafio.

\section{DESENVOLVIMENTO}

Consta uma matéria, (Jornal eletrônico Gr,2020) no período da pandemia, um grupo de rede social que promove com projeto "Mana Unidas", com diversas empreendedoras do ramo comercial de cosmético, lingerie, produtos industrializados, alimentício, tecnologia, startup, estético, onde, identifica um limiar, no tocante o suporte on-line para incentivar a reinvenção, com reflexos de crescimento no mercado, o objetivo do projeto é qualificar mulheres empreendedoras nessa região, promovendo cursos on-lines, com uso dos recursos tecnológicos das redes sociais, este ponto de cartada tem efeito positivo para incentivar o comércio, divulgam através do compartilhamento nas redes sociais, com intuito de aquecer às vendas, empreendedoras mulheres.

O levantamento de dados do observatório do IBGE, SEBRAE e JUCER, são dados quantitativos como constam os dados do observatório de indicadores do SEBRAE, no entanto, fica claro que o método qualitativo é o foco principal, foi criado um formulário para aplicar com base em perguntas abertas e fechadas. No cenário nacional, segundo os dados do Site Ibge, em 2020, o sexo feminino vem marcando seu papel no mercado de trabalho, no empreendedorismo, porém recebe cerca de $20,5 \%$ menos que os homens, porém os dados levantados pelo Sebrae, demonstra que, existe mais de 24 milhões de empreendedoras no país, sendo $25,4 \%$ do total de 94,2 milhões, ou seja, as mulheres empreendedoras comandam $34 \%$ das empresas abertas e gerenciam $48 \%$ das microempresas individuais (MEI), formais no Brasil.

No entanto, a aplicação do questionário na plataforma digital Facebook, nos grupos que compõe vendedoras em diversos ramos em Rondônia, certamente, a pesquisa visa investigar qualitativamente as empreendedoras no estado de Rondônia, qual o perfil em relação ao ramo de negócio, destaca-se o perfil comportamental das 
empreendedoras mulheres rondonienses nas relações das estruturas de poder entre homem e mulher, na disputa da temática de gênero.

\section{DADOS LEVANTADOS NO OBSERVATÓRIO DE INDICADORES DO IBGE}

Com base no levantamento, a seguir segue uma análise técnica de dados em porcentagem por cada semestre, em cada ano, usando comparativo, foi executado a condensação e apuração dos dados, assim coletados, segundo dados do IBGE, que consta no observatório de indicadores monitorados pelo observatório de indicadores monitorados do Data Sebrae indicadores, demonstra a descrição de dados estatísticos quantitativos.

Em que, identifica o sexo feminino, num destacado crescimento, das empreendedores, do sexo masculino em comparação.

O sexo feminino está em variável evolução, no trimestre 3/2017 foi avaliado em $37,48 \%$, no segundo levantamento 4/2017, os dados apontaram 37,48\%, no segundo levantamento de 4/2017, foi descrito em 37,85\%, no entanto, teve crescimento de $0,3 \%$ entre 3/2017 à 4/2017. Já de I/2018 foi identificado 37,69 em 2/2018 o levantamento foi de $37,71 \%$, com crescimento de o,02\%, no dado de $2 / 2018$ era de 37,71\%, em 2/2018, e o outro dado é que em 3/2018, avaliado em 37,83\%, houve crescimento do empreendedorismo de $0,12 \%$ de $2 / 2018$ à $3 / 2018$.

No trabalho, a perspectiva futura, o trabalho merece mensurar, futuramente, continuidade da pesquisa, se existe pesquisa no momento, o foco no método qualitativo seria encontrar através de pesquisa, questionário a concentração em porcentagem de empreendedoras, no caso, voltado para cada, qual ramo de negócio as mulheres empreendedoras estão em desenvolvimento e se reinventando. Com pesquisas no site, Sebrae de Rondônia (202I), foi identificado que existe o Programa Porto Velho empreende. A cada um ano tem um evento da prefeitura e demais órgãos e instituições fomentadoras, para efetivar um evento, uma feira estadual, a cada ano, em 2018, por exemplo, oportunizaram as empreendedoras o fortalecimento do trabalho formal e informal, além da capacitação para ensiná-las como angariarem crédito e investimento para os negócios embrionários. 
$\mathrm{Na}$ gestão pública, observa-se que observatório do Sebrae, monitora os indicadores, informações, dados quantitativos atualizados, indicadores que refletem, explica o crescimento do empreendedorismo feminino em Rondônia.

Para entendermos a temática geralmente, iremos pontuar algumas coisas, começaremos a estudar etimologicamente, a palavra empreendedorismo, ou seja, entender o sentido da palavra, o conceito, empreendedorismo, segundo Dicionário Aurélio on-line (2021) é: vocação, aptidão ou habilidade de desconstruir, de gerenciar e de desenvolver projetos, atividades ou negócios. Reunião dos conhecimentos e das aptidões relacionadas com essa capacidade. Etimologia (origem da palavra empreendedorismo).

Empreendedorismo, no entanto, o comércio e negócios estão em constante evolução, as mulheres neste fenômeno vem acompanhado e conquistado seu espaço no mercado de trabalho, seja formal e informal, tudo vale para sustentar a casa.

Além do preconceito de gênero, o sexo feminino, a mulher rondoniense, enfrenta um desafio na disputa binária dos sexos, na disparidade do gênero, a independência do sexo feminino, a concorrência nas funções, seja dona de casa, como era antigamente, esse papel libertador tem permitido ir em busca da luta pela sua emancipação e insubmissão financeira, a única saída é no espaço do mercado de trabalho, encontrar a oportunidade como recuso tangível.

O presente trabalho de pesquisa, visa descrever por meio do método qualitativo, pressupostos metodológicos, a ser analisado diante da coleta de dados para entender o perfil e qual comportamento das empreendedoras feminino, nas relações das estruturas de poder, nos polos dos gêneros, diante dos negócios na formalidade e informalidade.

Existem brasileiras sofrendo e há brasileiras que vem sofrendo para manter o mínimo no lar brasileiro, a única saída é sobressair, são as mulheres empreendedoras que se reconstroem, por meio do mercado de trabalho formal ou informal.

Segundo os estudo Engels (1984), traz na obra o feminino, seu papel e demanda pela socialização seja no processo primário ou secundário, nesta fase de controle social formal e informal na sociedade, logo, pela demanda do trabalho, doméstico e do cuidado com a família, as crianças, naquele processo histórico do contexto, o autor propõe a ideia que sustentava a família, que pertencia a si, no seu nicho, com base no trabalho análogo 
escravo, evidenciando a mulher na sociedade civilizatória, diante dessa estrutura de poder, surge a opressão do sexo feminino, pois o marido, burguês, invisibiliza por ser esposa, contribuir com afazeres doméstico e não visibilidade na troca dos papéis, a mulher integra o processo de transformação do crescimento da família, para constituição da prole, infelizmente a mulher era vista como um adereço, coadjuvante por ser esposa do marido, encontrando dificuldade na emancipação do próprio espaço de autonomia e dependência.

Agora, Engels (1984), a mulher passa a lutas pelos seus direitos sociais, tem independência financeira por meio do trabalho, subversiva e reativa as mudanças sociais. No tempo de Karl Marx, tinham trabalhadores, ganhavam salário muito baixo, nessa criação da sociedade onde o acesso dos bens econômicos a todos, ou seja, deve entender o processo civilizatório que deve entender uma estrutura de poder econômica que figurava o homem, muitas vezes machista, detentores do poder e capital, muitos vezes, ou sendo o marido burguês em relação ao o marido operário, um detentor dos meios de produção e o outro vendedor da força de trabalho para o seu bem estado social, que o estado atravessava no constitucionalismo social, o estado social, a garantia da preservação da promoção dos direitos sociais, a mulher na inserção no mercado de trabalho foi um momento de movimento social, no processo de luta de classe social.

Há de se discutir que, a libertação da mulher ocorre, através do trabalho é o meio para se reinventar como meio, para sobressair da violência doméstica, assim apontam os dados de violência doméstica do estado de Rondônia, assim como Acre subiu potencialmente.

Para podermos iniciar um processo de estruturação diante do convívio social, é necessário primeiramente incluir questões de diálogo, companheirismo, reciprocidade, processo de convivência; elementos que na ausência ou falha em aplicabilidade de alguns destes pontos, inicia um grande conflito, cujo a relação é vista como um problema, contudo, estes são os problemas sociais que causam sim um total desajuste ou disfunção na sociedade.

Esta falta de desarmonia na sociedade, acaba acarretando discussões, desentendimentos, bem como os delitos, as infrações às leis, uma quebra das normas sociais entre as partes envolvidas, provocando em muitos casos a retirada da liberdade e 
por fim o fim da vida para a mulher. A grande questão sobre a problemática atual em uma sociedade que instiga atos com a violência de gênero contra a mulher, tem tido tomada de força com apoiadores que incentivam a agressão e perpetuação da agressão contra a mulher.

Esse conflito pode ser observado por muitos que vai de fato de encontro a violência ao sexo feminino, alimentando assim presentemente, mesmo que o Brasil tenha avançado na reformulação da legislação da Maria da Penha. Uma forte aliada ao combate e tratativas é uma legislação ainda bem recente que está também em vigor,neste caso se trata da atual lei do feminicídio 13.104/15 punindo com rigor os criminosos que matam mulheres por questões relacionadas à violência doméstica.

A discriminação pelo fato deste ser humano ser do sexo feminino de nada irá adiantar se o discurso ainda inconsequente e desmoralizado continuar alimentando sim, a violência brutalmente, desrespeitosa e totalmente covarde.

O ponto central a ser entendido e aplicado ao longo do trabalho, é desenvolver sim, que deve-se trabalhar desde a educação de base, ou seja, a educação básica com crianças desde o primeiro momento com um convívio em sociedade. Uma criança que tenha sim uma estruturação e ser educada com princípios e aplicabilidade da ética e moral, respeitando sim, seu colega de ambiente escolar, ou até mesmo no próprio ambiente familiar que deve e sim é necessário trabalhar o diálogo e respeito e deste modo sabendo dos direitos e deveres, consequentemente terá ações canalizadas e assertivas para o futuro.

Em primeiro lugar, Durkheim explica através dos seus estudos o que é fato social, vale destacar ser a maneira de agir, pensar e de sentir do coletivo para o ser, que logo determina a força que exercem sobre os indivíduos, desde que ocorra no coletivo e respeite as normas de coercitividade, generalidade e exterioridade. Isto traz recordações e perceptividade de um pouco do funcionalismo estrutural de Durkheim, no caso a coercitividade, que diante do fato social, obriga de certa forma, a forçar, a enfrentar e lidar com o sistema opressor, tendo esta diferença do binarismo entre o dominador e dominado, porém todos sabemos que a mulher enfrenta essa disputa, certamente o feminicídio.

Vale destacar que, para: 
(DURKHEIN, 1983, p.4,) Entretanto, como os exemplos que acabamos de citar (regras jurídicas, morais, dogmas religiosos, sistemas financeiros, etc.) consistem todos em crenças e em práticas constituídas, poder-se-ia supor, com base no que precede, que só há fato social onde há organização definida. Mas existem outros fatos que, sem apresentar essas formas cristalizadas, têm a mesma objetividade e a mesma ascendência sobre o indivíduo. É o que chamamos de correntes sociais. Assim numa assembleia, os grandes movimentos de entusiasmo ou devoção que se produzem não têm por lugar de origem nenhuma consciência particular.

Trabalhar estes padrões existentes; padrões estes considerados externos a que estarão sempre existente independente da nossa existência, por exemplo, a interação social no coletivo é obrigatório desde que obedeça às regras da sociedade, o que as pessoas pensam, sentem ou concretizam independente de suas vontades individuais, o comportamento é estabelecido pela sociedade, não dá margem a escolhas.

Podemos entender que o texto, em estudo, vai de encontro com o fato social, pois demonstra pontos cruciais de modo de agir autoritário com base numa ideologia de governo que é austera, algo totalmente escroto que fere as normas de coercitividade e generalidade, mas infelizmente existe no momento, bem como discursos fora da diplomacia que traz consequência na política externa.

Trabalhar todo esse assunto tem por necessidade atentar-se aos padrões externo que sempre existirá independente da nossa existência, por exemplo, a interação social no coletivo é obrigatório desde que obedeça às regras da sociedade, o que as pessoas pensam, sentem ou elaboram independente de suas vontades individuais, o comportamento é estabelecido pela sociedade, não dá margem a escolhas.

Conforme dados do IBGE, existem I04 milhões de brasileiros que vivem em suas casas, em que a única fonte de renda é o auxílio emergencial do governo Federal. Assim, confirmam os dados do desemprego que saltou de $13.1 \%$ a 13 , 5\% no Brasil, segundo dados do Banco Mundial. A construção por meio da pesquisa, tende a responder algumas perguntas do cenário nacional e regional, sendo que a desigualdade regional é mais elevado, enfim o levantamento contará com a aplicação de questionário na plataforma digital Facebook, através dos grupos que, compõe diversas empreendedoras de vendas, em diversos ramos de negócio, a mulher rondoniense é um objeto de pesquisa que precisa ser estudada, pois, se reinventa no momento de crise sanitária, decreto da calamidade pública, a pandemia a Covid 19. Segundo (SEGATO, 2003), 
segue embasamento, logo abaixo, uma reflexão, onde explica na obra que o crime sangrento, mandato de estupro, define o uso e abuso do corpo feminino, a violência que todos os dias as mulheres passam, no sistema patriarcal e machista que impõe regras, mesmo em casos extremos de morte iminente, não deve ser tratada como objetificação $e$ corporificação, assim consta no artigo acadêmico, há nos autos elementos suficientes que a demandante está em risco de vida. Diante da era da sociedade da informação, no mundo globalizado, temos maior acesso à informação pelas tecnologias de comunicação, o que leva informação em tempo real, integral e instantâneo a esta civilização.

A sociedade está enfrentando o maior problema social de todos os tempos, a violência doméstica, aprender a conviver sem acirramentos dos polos binários, entre mulher e homem no mesmo espaço, em casa, entretanto o índice da violência contra as mulheres subiram, os números vêm aumentando, diante da pandemia global.

A grande questão a ser discutida e compreendida, de modo a discutir nesse primeiro momento uma problematização para tantos os desafios em viver em quatro paredes, onde há um lugar seguro, ou até mesmo um local que haja proteção, incorrem nos desafios dos infratores que vem atualmente causando sérias consequências à sociedade.

Esta falta de desarmonia na sociedade, acabam acarretando discussões, desentendimentos, bem como os delitos, as infrações às leis, uma quebra das normas sociais entre as partes envolvidas, provocando em muitos casos a retirada da liberdade e por fim o fim da vida para a mulher.

Em primeiro lugar, Durkheim explica através dos seus estudos o que é fato social, vale destacar ser a maneira de agir, pensar e de sentir do coletivo para o ser, que logo determina a força que exercem sobre os indivíduos, desde que ocorra no coletivo e respeite as normas de coercitividade, generalidade e exterioridade.

Isto traz recordações e perceptividade de um pouco do funcionalismo estrutural de Durkheim, no caso a coercitividade, que diante do fato social, obriga de certa forma, a forçar, a enfrentar e lidar com o sistema opressor, tendo esta diferença do binarismo entre o dominador e dominado, porém todos sabemos que a mulher enfrenta essa disputa, certamente o feminicídio.

Vale destacar que, para: 
(DURKHEIN, 1983, p.4,), Entretanto, como os exemplos que acabamos de citar (regras jurídicas, morais, dogmas religiosos, sistemas financeiros, etc.) consistem todos em crenças e em práticas constituídas, poder-se-ia supor, com base no que precede, que só há fato social onde há organização definida. Mas existem outros fatos que, sem apresentar essas formas cristalizadas, têm a mesma objetividade e a mesma ascendência sobre o indivíduo. É o que chamamos correntes sociais. Assim numa assembleia, os grandes movimentos de entusiasmo ou devoção que se produzem não têm por lugar de origem nenhuma consciência particular.

Trabalhar estes padrões existentes, é um exercício diário para conviver no coletivo, considerados externos que estarão sempre existentes, independente da nossa existência, por exemplo, a interação social no coletivo é obrigatório, desde que obedeça às regras da sociedade, o que as pessoas pensam, sentem ou realizam independente de suas vontades individuais, o comportamento é estabelecido pela sociedade, não dá margem a escolhas.

Outra pergunta é referente a violência doméstica que muitas mulheres empreendedoras, se refugiam na sua autonomia para sair desse estupro sangrento definido pela Segato, como o uso do corpo.

Em 2019 os números haviam reduzidos para 12,5\% em Rondônia, segundo dados do monitor da violência, podemos destacar que, em menos de um ano, os casos de feminicídio aumentaram numa larga escala para 42,85\% em Rondônia, no período de 2020, segundo dados da Sesdec. Diante da leitura de, Cessare Beccaria, um estudioso, italiano do século I8, afirmava que se há penas, logo existem proporções entre elas.

Para estruturar, o convívio social, inclusive tem uma coisa aí, que para ele é visto como um problema, contudo, os problemas sociais que causa um desajuste ou disfunção na sociedade, a desarmonia em sociedade, entendo como os delitos, as infrações, as leis, uma quebra das normas sociais.

Logo, considerando, o constante discurso: esquizofrênico, letal e preconceituoso de misoginia, machista do atual representante da nação brasileira, que pode-se ilustrar o crime cometido contra a Deputada Maria do Rosário, tempos passados, até hoje, cria e "reverbera vozes atônicas", a apoiadores que incentivam a agressão e perpetuação da agressão contra a mulher, isso vai de encontro a violência ao sexo feminino, por mais 
que o Brasil tenha atacante na reformulação da legislação da Maria da Penha e, em vigor a atual lei do feminicídio 13.104/I5 que pune com rigor os criminosos que matam mulheres por questões relacionadas à violência doméstica, a discriminação pelo fato de ser do sexo feminino, nada adianta se o discurso inconsequente de verborragia permanece, no entanto, o ponto central que deve-se trabalhar é na educação de base, uma criança bem-educada sabendo dos direitos e deveres, consequentemente terá ações canalizadas e assertivas para o futuro.

Mas ao ler os noticiários, analisa-se que, esta investida, deve ser rota, lembra um pouco do funcionalismo estrutural de Durkeimen, no caso a coercitividade, que diante do fato social, obriga de certa forma, a forçar, a enfrentar e lidar com o sistema opressor, ao ocorrer esta diferença do binarismo entre o dominador e dominado, porém todos sabem que a mulher enfrenta essa disputa, certamente o feminino, é o que move a nossa nação, tem melhores indicadores de estudos, mas infelizmente tem pouca defesa, não é esquecida, no entanto, invisibilidade pelos nossos representantes, assim como reverbera vozes atônitas, inclusive da Ministra Damares, menino Azul e menina Rosa, menino brinca de carrinho e menina de boneca.

A mulher deve ter seu lugar, ser submissa ao homem conforme os ditames da bíblia, assim falado pela Ministra: Damares, a bancada evangélica, Malafaia e Edir Macedo, ambos defendem esta concepção. Infelizmente, no momento, o representante da nação dispensa a empresa Pfizer 70 milhões de vacinas e deixa esperando o representante no Planalto do Brasil, é um ato atentatório, um crime cometido, agora está instaurada CPI para investigar os atos de improbidade de gestores públicos em plena pandemia global no Brasil, voltado para relações internacionais motivos de chacota, podendo receber sanções internacionais da ONU - Organização da nação internacional, por não assegurar os direitos fundamentais e fazer a política doméstica, diante da política externa do país.

Com base nos pressupostos citados, no tocante ao capitalismo, infelizmente é necessário, mas favorece a desigualdade social, as disfunções na sociedade, segundo Marx, naquilo que consiste em maneira desigual a concentração de renda, sempre será um problema na sociedade, pois o: 'de cima sobe, o debaixo desce', enfim estes efeitos têm fatores socioeconômicos elevados de quem tem mais poder aquisitivo, no momento 
da crise sanitária, que atravessa o país, pois está nas mãos dos detentores de riqueza, desconcentração de riqueza é um problema relevante, assim fica exacerbado os indicadores sociais da fome, desemprego, marginalidade, em plena pandemia, em decorrência disto, o brasileiro se reinventa a todo momento, segundo dados do Dieese, aumentou em cerca de 50\% na pandemia, Brasil a informalidade, ou seja, o brasileiro se reinventa, mas precisa efetividade, eficácia e eficiência na ação dos representantes para fomentar uma política efetiva de vacinação em massa, dos mais de 212 milhões de habitantes, pois desde vacinarem todos, a máquina voltará a funcionar, sem vidas, não existe nação e nem economia.

Assim define o autor:

(MARX, 2013 p.47-18) Mas a humanização da natureza nem sempre tem sido um processo harmônico. Marx foi dos primeiros a apontar o caráter predador da burguesia, com reiteradas referências, por exemplo, à destruição dos recursos naturais pela agricultura capitalista. Sob esse aspecto, merece ser considerado precursor dos modernos movimentos de defesa da ecologia em benefício da vida humana. Do ponto de vista da Antropologia, o que sobreleva é a relação do homem com a natureza por meio do trabalho e a humanização sob o aspecto de autocriação do homem no processo de transformação da natureza pelo trabalho.

Apesar que, não é uma tarefa fácil, mas o empreendedorismo feminino é uma realidade, vem crescendo conforme dados, no Brasil, diante do foco da geração de renda, frente os negócios no país é o maior desafio, logo a natureza humana, a desigualdade social é um problema na sociedade, a mulher, em caso específico requer sua "autoindependência" para não sofrer opressão psicológica, pois muitas mulheres se prendem emocionalmente a um relacionamento abusivo, em detrimento da dependência total ou parcial, no tocante a renda financeira do homem, em decorrência mulheres estão empreendendo, com fruto de geração de renda frente os negócios no país, em Rondônia não tem sido diferente como os dados do Sebrae e IBGE, enfim, destacamos que o empoderamento feminino, a autoestima elevada para fazer girar a renda, o capital de giro, vai contra aquele conhecimento popular e religioso, que o homem que mantém a casa e que sustenta a casa, colocando a mulher como o espelho do homem, porém como submissa, a produção cultural, coanduna com entendimento, a música, do cantor Erasmo Carlos, segue o trecho abaixo, que vai no sentido cultural do machismo enraizado ao compor no trecho da música, que faz inclusive uma oposição, revendo valores morais nos padrões culturais. 
Com a produção cultural, a música de: (CARLOS, I98I) “Dizem que a mulher é o sexo frágil, mas que mentira absurda! Eu que faço parte da rotina de uma delas...,Quando chego em casa à noitinha, quero uma mulher só minha...para quem deu luz não tem mais jeito Porque um filho quer seu peito, mulher, mulher Do barro de que você foi gerada. Pra decantar você nessa canção, $\mathrm{Na}$ escola em que você foi ensinada, jamais tirei um dez, Sou forte mas não chego aos seus pés.

Identificamos machismo impregnado na cultura popular brasileira, por meio da manifestação cultural.

\section{CONSIDERAÇÕES FINAIS}

Os representantes, Bolsonaro e o Ministro, atualmente, não fazem fortalecer a política doméstica, não cumprem com os objetivos políticos para consolidação da política externa, segundo a ONU, o Brasil tem o maior desafio de diminuir o alto índice de violência doméstica contra a mulher, segundo a política exterior, país nenhum investe numa nação que não trata a mulher com menosprezo e desigualdade (um caso de feminicídio, a cada 7 horas), podemos dizer ser algo para pensar e refletir, cadê as políticas sociais e a promoção da lei nas escolas, certamente não resultar na melhoria dos indicadores sociais é temerário, pois para melhorar as relações com os demais países, tem que respeitar os: protocolos, acordos, tratados, convenções, infelizmente como ocorre o desrespeito da "negação", tudo para não criar e ampliar as políticas públicas para população brasileira, o representante dar mais importância as questões ideológicas de direita, com a austeridade e totalitarismo que diminui sua popularidade cada dia, e causa uma insegurança e instabilidade nacional para investidores (rombo na reserva nacional).

Assim como afronta a soberania nacional, qual país vai investir numa nação na, qual a violência contra as mulheres está em progressão, sendo ser um fator condicionante da ONU para uma nação desenvolvida ter redução nesses índices, ou seja, criar políticas de incentivos e valorização as mulheres aguerridas brasileiras que mantém nossa nação em pé. 


\section{REFERÊNCIAS BIBLIOGRÁFICAS}

BECCARIA, Cesare. Dos Delitos e das Penas: São Paulo: Martin Claret, 200r.

DURKHEIM, Émile. As Regras do Método Sociológico. São Paulo, Ed. Abril Cultural, 1983, IOIP

ENGELS , FRIEDRICH. A origem da família, da propriedade privada e do estado. Rio de janeiro: Civilização brasileira, 1984. 91 p.

MARX, Karl. O Capital: Crítica da economia política. Livro I: O processo de produção do capital. Trad. Rubens Enderle. São Paulo: Boitempo, 2013.

MARTINS, Pedro Paulo Almeida; NASCIMENTO, Marla Anaiê Belfort. O PROBLEMA SOCIAL COM A VIOLÊNCIA DE GÊNERO COM A MULHER: UM DESAFIO NA SOCIEDADE COM O ENFRENTAMENTO DESENFREADO POR QUESTÕES E CUIDADOS COM O DIREITO À VIDA. Revista IberoAmericana de Humanidades, Ciências e Educação- REASE, São Paulo, ano 2021, v. 7, ed. $5, \quad$ p. 792-791, 4 maio 2021. Disponível em: $<$ https://periodicorease.pro.br/rease/article/view/1240/563>

Acesso em:I9 de Dez de 202r SAUTU, RUTH. Todo es Teoría: Objetivos y métodos de investigácion. I. ed. Buenos Aires: Lumiere, 2003. 98 p.

TAROZZI, MASSIMILIANO. O que é Grounded: metodologia de pesquisa e teoria fundamentada nos dados. Rio de Janeiro: Vozes, 2011. 43 p.

Erasmo Carlos- Mulher Sexo Frágil. Disponível em: $<$ https://www.youtube.com/watch?v=jtsgXdA3hPo. Acesso em 24 de Fevereiro de 202I

Disponível em: $<$ https://economia.ig.com.br/2019-03-08/diferenca-salarial-entremulheres-e-homens.html. Acesso em 24 de Fevereiro de 202I

Disponível em:<https://gi.globo.com/ro/rondonia/noticia/2021/or/27/em-um-anocasos-de-feminicidio-aumentam-4285percent-em-rondonia.ghtml. Acesso em 24 de Fevereiro de 2021

Disponível em:<https://gi.globo.com/ro/rondonia/noticia/2020/03/o5/numero-defeminicidios-cai-I25percent-em-rondonia-durante-2019.ghtml. Acesso em 24 de Fevereiro de 2021

Fonte:

em: $<$ http://mercosursocialsolidario.org/valijapedagogica/archivos/hc/I-

Disponvível aportesteoricos/2.marcosteoricos/3.libros/RitaSegato.LasEstructurasElementalesDeLa Violencia.pdf $>$ Disponível em: $<$ SEGATO, Rita. Laura. Las estructuras elementales de la violencia: contrato y estatus en la etiología de la violência. In: SEGATO, Rita Laura. 
Las estructuras elementales de la violência. I. ed. Bernal: Universidad Nacional de Quilmes, 2003.> Acesso em 30 de Abril de 2021.

Disponível em:<https://diariodonordeste.verdesmares.com.br/vem-empreender/24milhoes-de-mulheres-sao-donas-de-empresas-no-brasil-254-do-total-1.3013123 Acesso em 24 de Fevereiro de 2021

Disponívelem:<http://sistema.datasebrae.com.br/sites/novo_datasebrae/\#Empreended ores/Sexo_dos_empreendedores/Grafico Acesso em 24 de Fevereiro de 2021

Disponível em:<https://gi.globo.com/ro/rondonia/noticia/2020/o8/o5/iniciativaajuda-mulheres-empreendedoras-em-porto-velho-a-melhorar-vendas-durante-apandemia.ghtml Acesso em 24 de Fevereiro de 2021

Disponível em:<https://diariodonordeste.verdesmares.com.br/vem-empreender/24milhoes-de-mulheres-sao-donas-de-empresas-no-brasil-254-do-total-I.3013123 Acesso em 24 de Fevereiro de 2021

Disponível em:<http://www.sebrae.com.br/sites/PortalSebrae/sebraeaz/mulheres-enegocios-a-forca-do-empreendedorismo-

feminino,56ff2a53c6d8o7roVgnVCMrooooo4coo2ioaRCRD Acesso em 24 de Fevereiro de 202I

Dicionário Aurélio on-line 2021 dicionário https://www.dicio.com.br/empreendedorismo/\#: :text=Significado\%2ode\%2oEmpreen dedorismo\&text $=$ Voca\% $\mathrm{C}_{3} \% \mathrm{~A}_{7 \%} \mathrm{C}_{3} \% \mathrm{~A}_{30}$ 202C20aptid\%C3\%A30\%200u\%2ohabilidad e\%20de,Empreendedor\%20\%2B\%20ismo. Acesso em 24 de Fevereiro de 202I 